\title{
Late Failure of Pulmonary Artery Banding
}

\author{
Tsutomu Imaizumi, M.D. and Eliot Schecter, M.D.
}

\begin{abstract}
Summary
Pulmonary artery banding was performed on an 11 -year-old female with a large patent ductus arteriosus to control pulmonary hypertension. At catheterization 3 years later the band on the right pulmonary artery was present. At catheterization 13 years later the right pulmonary artery band could no longer be demonstrated.
\end{abstract}

\section{Additional Indexing Words :}

Congenital heart disease Patent ductus arteriosus Pulmonary hypertension

\begin{abstract}
A new group of "iatrogenic" heart diseases are being seen as children operated upon during the early years of cardiac surgery are reaching adulthood. The late results of implanting prosthetic materials and of altering hemodynamics are just now becoming evident. One of the earliest procedures, banding of the pulmonary artery, was first performed in 1951 by Muller and Dammann in a 4-month-old infant with a single ventricle and increased pulmonary blood flow. ${ }^{1)}$ Since then banding has become an accepted temporary treatment for infants in intractable congestive heart failure with septal defects and increased pulmonary blood flow due to a large left to right shunt while awaiting corrective surgery and has also been suggested as a palliative procedure for patients with inoperable defects. ${ }^{2), 3)}$ Since 1952 the technique has been modified and many banding materials have been used: cellophane, silk, cotton umbilical tape, nylon, and Dacron. There have been complications associated with each of these, including severe fibrosis, incorporation and calcification. In several reported cases ${ }^{4,5)}$ the band has cut through the vessel wall and in another ${ }^{6}$ it migrated from the site of banding resulting in "debanding" of the PA. If banding is to be considered for palliation the late results of this proccdure must be known. To our knowledge, a case of late spontaneous release of the band after initial success has not been reported.
\end{abstract}

From the Cardiovascular Section, Department of Medicine, Veterans Administration Hospital and University of Oklahoma Health Science Center, Oklahoma City, Oklahoma, U.S.A.

Address for reprint: Tsutomu Imaizumi, M.D., Research Institute of Angiocardiology and Cardiovascular Clinic, Kyushu University Medical School, 3-1-1 Maidashi, Higashi-ku, Fukuoka 812, Japan.

Received for publication July 12, 1979. 


\section{Case Report}

A 25-year-old white female, was referred to University Hospital and Clinics because of possible pulmonary emboli with respiratory failure.

Her mother's antinatal course and her infant history are unknown. In 1956, at the age of 4 years she underwent cardiac cathetcrization. Pulmonary hypertension was found, but a definite diagnosis was not established. In 1963 at the age of 11 years she was restudied and was found to have a patent ductus arteriosus (PDA). At that time her right pulmonary artery (RPA) pressure was 140/80 $\mathrm{mmHg}$ with mean of $100 \mathrm{mmHg}$. Bilateral pulmonary artery banding was performed because of pulmonary hypertension. Although not specifically mentioned in the patient's record, cotton umbilical tape was routinely used for banding at the time this patient was operated upon.

Cardiac catheterization and pulmonary arteriogram were performed 3 years later in 1966. RPA pressure had decreased to $80 / 60 \mathrm{mmHg}$ while main PA pressure remained elevated at $135 / 75 \mathrm{mmHg}$. Pulmonary angiogram (Fig. 1) confirmed the localized constriction of the RPA due to the band. At that time physical examination revealed a systolic ejection murmur. Definitive corrective surgery of her PDA was advised, but the patient refused.

She was not seen in follow-up for 10 years when her third full term pregnancy was complicated by pulmonary emboli and respiratory failure. After staisfactory recovery she was able to resume household duties with only moderate fatigue. She denied orthopnea, PND, pedal edema, chest pain, and shortness of breath. On physical examination in August 1976, vital signs were normal. She was in no acute distress but was cyanotic. Clubbing of the fingers was present. The jugular venous pulse was normal. She had a prominent right ventricular impulse. Splitting of $\mathrm{S}_{2}$ was fixed and narrow. $\mathrm{P}_{2}$ was louder than $\mathrm{A}_{2}$. A pulmonic ejection sound

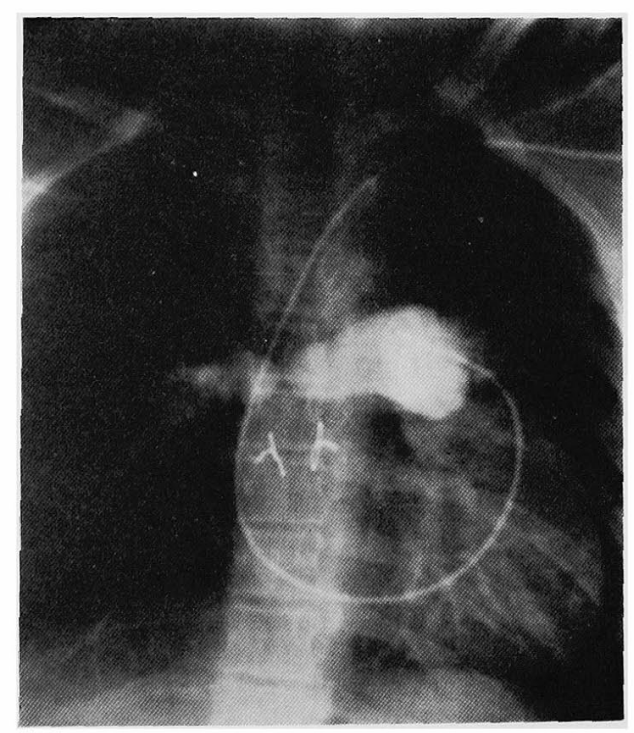

Fig. 1. Pulmonary angiogram demonstrates tight constriction of the right pulmonary artery. 


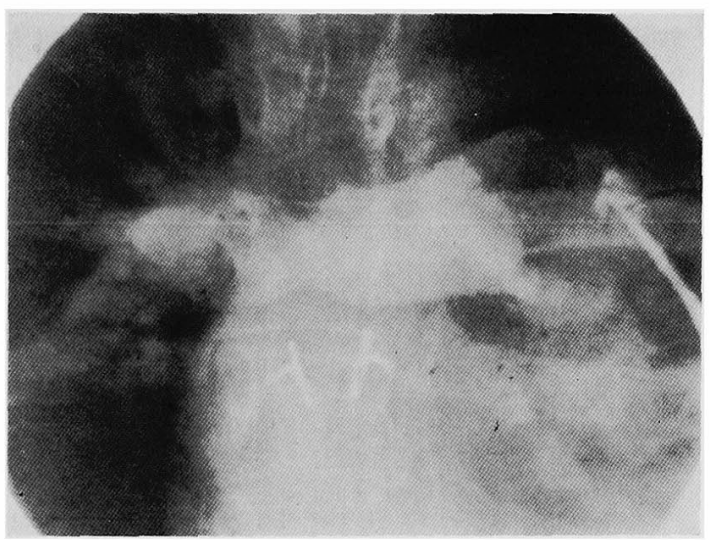

Fig. 2. Pulmonary angiogram demonstrates the released constriction with mild residual narrowing of the right pulmonary artery.

was present. The previously noted systolic murmur was no longer heard. Hct was $55.0 \%$ with $\mathrm{Hg}$ of $19.4 \mathrm{Gm}$. Blood gases on room air revealed a $\mathrm{PO}_{2}$ of $62 \mathrm{mmHg}$. EKG demonstrated right ventricular hypertrophy as did her chest X-ray. At catheterization distal right pulmonary artery pressure was $125 / 76 \mathrm{mmHg}$, proximal right pulmonary artery pressure was $130 / 75 \mathrm{mmHg}$, and main pulmonary artery pressure was $135 / 75 \mathrm{mmHg}$. Total pulmonary resistance was 2262 dynes sec $\mathrm{cm}^{-5}$. She had a right to left shunt. Cautious pulmonary angiogram with hand injection of 20 cc's of renografin 76 (Fig. 2) revealed loss of the previous RPA narrowing. No intraluminal filling defect was noted.

\section{DisGuSSION}

Pulmonary artery banding was originally proposed as a temporary measure to reduce pulmonary blood flow in patients with large left to right shunt until body size, pulmonary resistance, and other factors were favorable for repair of the basic defect and release of the band. In some cases, either because the basic defect cannot be corrected, ${ }^{2)}$ or because (as in our case) the patient refuses surgery, the band may be left in place for a long time. The late results of this iatrogenic pulmonary artery obstruction are, therefore, important. The progression of pulmonary vascular disease in our patient is probably due to the release of the constriction. In previously reported cases failure of the band occurred early. In the case reported by Verel ${ }^{6}$ failure due to migration of the band into the lumen had occurred within 2 and 3/12 years of operation, while in the 3 cases reported by Rohmer ${ }^{4}$ migration was documented at 4 months, $63 / 12$ years, and $53 / 12$ years. Hunt et al ${ }^{2}$ gave followup data on 28 cases studied from 1 to 6.5 years post-op. In 3 cases there was no decrease in left to right shunt but the gradients were not mentioned and in 5 cases there was no "outflow gradient". In 1 of these cases was there 
documented early success with late failure. In our patient successful banding was demonstrated 3 years after operation with failure 13 years post-operatively. The late failure may be related to the material used for banding since Cordell ${ }^{7}$ ) showed that different materials elicited different responses. However Berry ${ }^{5}$ ) suggested that any band tight enough to produce a significant reduction in pressure would produce ischemic injury of the underlying pulmonary artery wall. Further Rohmer ${ }^{4}$ reported migration of band into PA with either teflon or umbilical tape. The eventual failure of banding in our case is of interest since no other follow-up of this length has been reported.

A systolic flow murmur is indicative of pulmonary artery constriction due to the band. This was present at the time of our patient's first follow-up catheterieation. Loss of the murmur probably indicates loss of effective constriction. As was evident at the time of our patient's second study this may well prove to be an important finding in following patients in whom long term or permanent banding is used to palliate defects not amenable to complete correction since early recognition of band failure may allow re-operation before progressive pulmonary vascular changes occur.

\section{AGKNOWLedgments}

The authors wish to acknowledge the critical and valuable review of this report by Dr. G. Rainey Williams, Professor and Chairman, Department of Surgery, University of Oklahoma Health Sciences Center, and the secretarial assistance of Mrs. Joyce Beller in preparation of the manuscript.

\section{REFERENGES}

1. Dammann JF Jr: The treatment of certain congenital malformations of the heart by the creation of pulmonic stenosis to reduced pulmonary hypertension and excessive pulmonary blood flow. Surg Gynec 95: 213, 1952

2. Castaneda A, Formanek G, Hunt CE, Levine MA, Moller JH: Banding of the pulmonary artery, results in 111 children. Circulation 43:395, 1971

3. Idriss FS, Paul MH, Riker WL: Banding of the pulmonary artery, A palliative surgical procedure. J Pediat Surg 3: 465, 1968

4. Brom AG, Nauta J, Rohmer J: Bands inside the pulmonary artery. Ann Thor Surg 3: 449, 1967

5. Berry CL: Changes in the wall of the pulmonary artery after banding. J Path 99: 29, 1969

6. Emery JL, Taylor DG, Verel D: Failure of pulmonary artery banding due to migration of the band. Thorax 25: 126, 1970

7. Cordell AR, Suh SH: The pulmonary artery lesion after banding. Ann Surg 5: 805, 1974 